\section{Parâmetros da areia que influenciam a consistência e a densidade de massa das argamassas de revestimento}

\author{
Sand parameters influencing the consistency \\ and bulk density of renderings mortars
}

Helena Carasek ${ }^{1}$, Renato Costa Araújo ${ }^{2}$, Oswaldo Cascudo ${ }^{1}$, Renato Angelim ${ }^{3}$

\author{
${ }^{1}$ PPG - GECON - EECA - Universidade Federal de Goiás (UFG) - CEP: 74605-220, Goiânia, GO \\ e-mail: hcarasek@gmail.com; ocascudo@gmail.com \\ ${ }^{2}$ Complexo Tecnológico da Engenharia Civil - CTEC - IFG CEP 74968-755, Aparecida de Goiânia, GO \\ e-mail: renato.costa@ifg.edu.br \\ ${ }^{3}$ Laboratório de Geotecnia - LabGeo - EECA - UFG - CEP 74605-220, Goiânia, GO -e-mail: tecnoeng@gmail.com
}

\section{RESUMO}

O consumo de areias de britagem para produção de argamassas vem aumentando, uma vez que as jazidas de areia natural estão cada vez mais escassas e que a exploração dessa areia gera grande impacto ambiental. Nesse sentido, o objetivo deste trabalho é verificar a influência do emprego de areias de britagem de diferentes origens e mineralogias nas propriedades de argamassas de revestimento no estado fresco. Com base em uma ampla caracterização de agregados originários de diferentes fontes litológicas, a pesquisa visou avaliar quais parâmetros da areia melhor explicam os comportamentos de consistência e de densidade de massa da argamassa. O estudo foi realizado com cinco areias, sendo uma areia natural e quatro de britagem oriundas de rochas de diferentes litologias (granito, dolomito, micaxisto e quartzito). Além da caracterização granulométrica e da determinação dos índices físicos das areias, foram realizadas análises morfoscópica e petrográfica, bem como a determinação do ângulo de atrito interno por meio do ensaio de cisalhamento direto. Para verificar o efeito das características das areias nas propriedades da argamassa no estado fresco, empregou-se uma mistura 1:1:6 (cimento:cal:areia, em volume), tendo-se realizados os ensaios de determinação do índice de consistência na mesa ABNT, penetração do cone e densidade de massa. As principais conclusões obtidas ressaltam que a porosidade (vazios entre partículas e grãos de areia) e a massa unitária da areia são os parâmetros que melhor se correlacionam com a consistência e a densidade de massa das argamassas, o que é explicado pela alteração imposta no volume de pasta das argamassas devido ao volume de vazios deixado pelos grãos das areias.

Palavras-chave: argamassa, areia, consistência, densidade de massa, massa unitária.

\section{ABSTRACT}

The use of manufactured sands in the production of mortars has been increasing in the last years, since the natural sand deposits are becoming increasingly scarcers and the exploitation of sand generates high environmental impact. In this sense, the objective of this work is to verify the influence of manufactured sands from different origins and mineralogies on the properties of rendering mortars in the fresh state. Based on an extensive characterization of aggregates from different lithological sources, the research aimed to assess which sand parameters explain better the mortar behaviors of consistency and bulk density. The study was performed with five sands: one natural sand and four manufactured sands originated from rocks of different lithologies (granite, dolomite, mica-schist and quartzite). In addition to the particle size characterization and the determination of the physical indices of sands, a morphoscopic analysis and a petrographic analysis were also carried out as well as the determination of internal friction angle obtained from direct shear test, used for soils. To verify the interference of sand characteristics on the mortar properties in fresh state, it was employed a mix proportion 1: 1: 6 (Portland cement:lime:sand, by volume), and it was performed the tests to determine the consistency index in ABNT table (flow table), the cone penetration (ASTM) and the bulk density. The main conclusions point out that the porosity (voids among particles and sand grains) and the apparent dry density of sand are the best parameters to explain the variation of mortars consistency and bulk densi- 
ty. This is explained by the change imposed on the paste volume of mortars due to the voids volume left by the sand grains arrangement.

Keywords: mortar, sand, consistency, bulk density, apparent dry density.

\section{INTRODUÇÃO}

Os agregados para argamassa devem ser selecionados com cautela, uma vez que eles representam cerca de $60 \%$ a $80 \%$ do consumo dos materiais da argamassa pronta, em massa, resultando em significativa influência no seu comportamento no estado fresco, bem como no desempenho do revestimento [1]. Por essa razão, a influência da composição granulométrica e de outras características das areias naturais em argamassas têm sido estudadas ao longo do tempo [2,3,4].

O Brasil não está entre os países que mais consomem agregados, mas certamente é um dos que mais agressão impõem à natureza devido à forma descontrolada de extração de minerais para a construção civil, principalmente a areia natural de rio. Estima-se que a extração de areia natural no Brasil seja da ordem de 320 milhões de metros cúbicos por ano, grande parte de forma ilegal. Além da informalidade prejudicar muito o desenvolvimento de uma região, não há areia suficiente em face da demanda atual de construções, de modo que a natureza sofre consequências importantes como agressão à calha dos rios e às suas margens [5].

A substituição da areia natural pela areia de britagem (também denominada de areia artificial) tem sido a solução encontrada pela indústria da construção civil para resolver o problema do esgotamento das jazidas, bem como o efeito do impacto ambiental gerado pela sua extração. Uma vantagem das areias britadas é que elas apresentam menor variabilidade das propriedades e características, como granulometria, forma e, ainda, a ausência de impureza como matéria orgânica e presença de argila em torrões. Em contrapartida, a forma angulosa e muitas vezes lamelar de suas partículas, além da elevada presença de finos, podem influenciar nas propriedades das argamassas, principalmente na sua trabalhabilidade. Estas características dependem do tipo de rocha de origem e do tipo de britador utilizados.

Vários trabalhos têm se dedicado ao estudo das areias oriundas de britagem de rocha nas propriedades das argamassas, como forma de contribuir para o uso corrente desse tipo de agregado na produção das argamassas de construção $[5,6,7,8,9,10,11,12,13,14,15]$.

Especificamente em relação à interferência nas propriedades do estado fresco das argamassas, o efeito da forma das partículas, da mineralogia e do teor de finos do agregado foi avaliado preliminarmente por Cascudo e Carasek [16]. Embora este trabalho tenha avaliado o efeito de agregados finos naturais (saibros) ele deu importante suporte aos estudos neste tema.

O presente trabalho, portanto, avaliou a influência do emprego das areias de britagem de diferentes origens litológicas e mineralogias nas propriedades da argamassa no estado fresco. A hipótese é de que a consistência das argamassas no estado fresco tem seu comportamento associado a parâmetros da areia como: ângulo de atrito e fator de empacotamento dos grãos. É de conhecimento que o empacotamento tem significativa influência sobre o índice de vazios, porosidade e massa unitária do agregado (na condição seca e solta), sendo, por sua vez, alterado pela forma e geometria das partículas, além da distribuição granulométrica. Assim, com base em uma ampla caracterização dos agregados de diferentes mineralogias, a pesquisa teve como objetivo avaliar quais parâmetros da areia melhor explicam os comportamentos de consistência e de densidade de massa da argamassa.

\section{PROGRAMA EXPERIMENTAL}

\subsection{Materiais}

Para atingir os objetivos, buscou-se utilizar areias existentes no mercado com composições mineralógicas distintas para realização do programa experimental, sendo uma areia natural e quatro areias de britagem (Figura 1). A areia natural é oriunda do leito do rio Caiapó, no trecho próximo à cidade de Iporá, no Estado de Goiás, e as areias de britagem são provenientes de diferentes pedreiras: granito da cidade de Guapó - GO, dolomito de Pedro Leopoldo - MG, micaxisto de Aparecida de Goiânia - GO e quartzito de Anápolis - GO.

As areias foram selecionadas de forma a representar uma gama distinta de agregados miúdos, com diferentes características físicas e mineralógicas, que pudessem impactar as propriedades das argamassas no estado fresco. A única condição fixa para a seleção desses agregados foi a definição de areias consideradas finas, com granulometria adequada para a produção de argamassas de revestimento. Uma ressalva final é mister de ser colocada para as areias de britagem. Os diferentes processos de britagem ou de cominuição das rochas, que levam à obtenção dessas areias, introduzem variações nos aspectos de forma e de esfericidade 
dos grãos, assim como na distribuição granulométrica e finura das partículas obtidas, interferindo, assim, nas características finais das areias, em adição às mencionadas características litológicas das rochas de origem e aos aspectos mineralógicos dos grãos. Como não se constituiu objetivo do trabalho a avaliação dos diferentes tipos ou processos de britagem na produção das areias, é possível que esses processos tenham sido diversos na presente situação e que eles tenham, de alguma forma, influenciado as características finais das areias estudadas, sem que isso comprometa a verificação da hipótese apresentada neste trabalho.

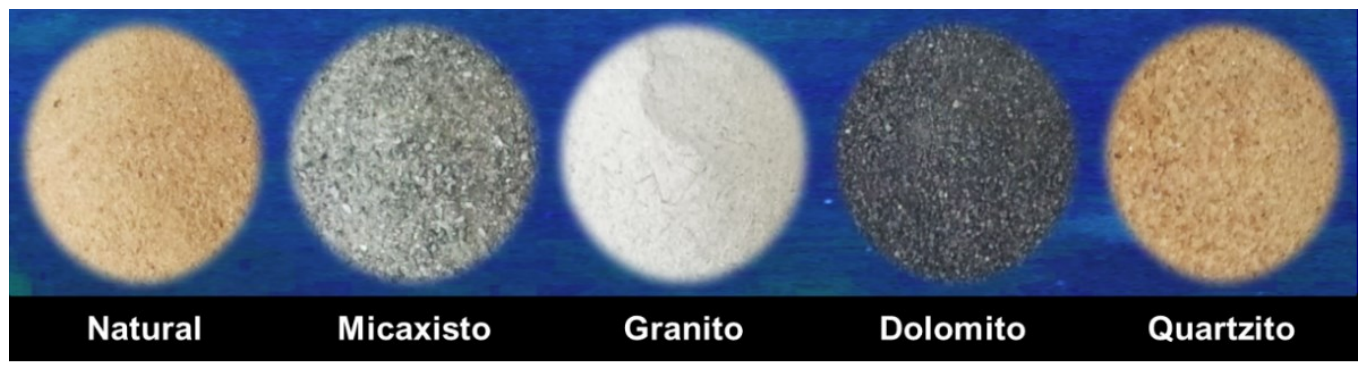

Figura 1: Areias estudadas.

Para a produção das argamassas, além das diferentes amostras de areia, foram utilizados os seguintes materiais como ligantes: um cimento Portland CP II F-32 e uma cal hidratada tipo CH-I, caracterizados nas Tabelas 1 e 2 .

Tabela 1: Caracterização física e química do cimento Portland CP II F - 32

\begin{tabular}{|c|c|c|c|}
\hline PROPRIEDADES & $\begin{array}{l}\text { MÉTODOS DE } \\
\text { ENSAIO }\end{array}$ & $\begin{array}{l}\text { CARACTERIZAÇÃO } \\
\text { DA AMOSTRA }\end{array}$ & $\begin{array}{l}\text { PARÂMETROS } \\
\text { NORMATIVOS } \\
\text { DA NBR 11578: } 1991 \\
\end{array}$ \\
\hline Massa unitária $\left(\mathrm{g} / \mathrm{cm}^{3}\right)$ & NBR NM 23: 2001 & 1,05 & - \\
\hline Massa específica $\left(\mathrm{g} / \mathrm{cm}^{3}\right)$ & NBR NM 23: 2001 & 2,97 & - \\
\hline Finura Blaine $\left(\mathrm{cm}^{2} / \mathrm{g}\right)$ & NBR NM 76: 1998 & 4380 & $\geq 2600$ \\
\hline Resíduo na peneira \# 200, 75mm (\%) & NBR 11579: 1991 & 0,8 & $\leq 12$ \\
\hline Resíduo na peneira \# 325, 45 mm (\%) & NBR 12826: 1993 & 5,8 & - \\
\hline Tempo de início de pega (h, min) & NBR NM 65: 2003 & $2 \mathrm{~h}, 20 \mathrm{~min}$ & $\geq 1 \mathrm{~h}$ \\
\hline Tempo de fim de pega $(h, \min )$ & NBR NM 65: 2003 & $3 \mathrm{~h}, 00 \mathrm{~min}$ & $\leq 10 \mathrm{~h}$ (facultativo) \\
\hline $\begin{array}{l}\text { Resistência à compressão } \\
3 \text { dias }(\mathrm{MPa})\end{array}$ & \multirow{3}{*}{ NBR 7215: 1996} & 23,0 & $\geq 10$ \\
\hline 7 dias $(\mathrm{MPa})$ & & 31,5 & $\geq 20$ \\
\hline $28 \operatorname{dias}(\mathrm{MPa})$ & & 40,0 & $\geq 32$ \\
\hline Teor de $\mathrm{MgO}(\%)$ & NBR NM 14: 2012 & 1,04 & $\leq 6,5$ \\
\hline Teor de $\mathrm{SO}_{3}(\%)$ & NBR NM 14: 2012 & 2,65 & $\leq 4,0$ \\
\hline
\end{tabular}

Tabela 2: Caracterização física e química da cal hidratada CH-I.

\begin{tabular}{l|l|l|l}
\hline PROPRIEDADES & $\begin{array}{l}\text { MÉTODOS DE } \\
\text { ENSAIO }\end{array}$ & $\begin{array}{l}\text { CARACTERIZAÇÃO } \\
\text { DA AMOSTRA }\end{array}$ & $\begin{array}{l}\text { PARÂMETROS } \\
\text { NORMATIVOS DA } \\
\text { NBR 7175: 2003 }\end{array}$ \\
\hline Anidrido Carbônico $\left(\mathrm{CO}_{2}\right)(\%)$ & NBR 6473: 2003 & 4,05 & $\leq 5 \%$ \\
\hline Óxidos de Ca e $\mathrm{Mg}$ não hidratados (\%) & NBR 6473: 2003 & 5,96 & $\leq 10$ \\
\hline Óxidos totais na base de não voláteis (\%) & NBR 6473: 2003 & 97,04 & $\geq 90$ \\
\hline Finura peneira 0,6 $\mathrm{mm}(\%)$ & NBR 9289: 2000 & 0,3 & $\leq 5$ \\
\hline Finura peneira 0,075 $\mathrm{mm}(\%)$ & NBR 9289: 2000 & 9,1 & $\leq 10$ \\
\hline Plasticidade $(\%)$ & NBR 9206:2003 & 120,8 & $\geq 110$ \\
\hline Massa unitária $\left(\mathrm{g} / \mathrm{cm}^{3}\right)$ & NBR NM 23: 2001 & 0,45 & - \\
\hline Massa específica $\left(\mathrm{g} / \mathrm{cm}^{3}\right)$ & NBR NM 23: 2001 & 1,05 & - \\
\hline
\end{tabular}




\subsection{Caracterização das areias}

Inicialmente, realizou-se a caracterização física das cinco amostras de areia, por meio da determinação da composição granulométrica, da massa unitária e da massa específica, conforme procedimentos preconizados pelas normas ABNT NBR NM 248 [17], ABNT NBR NM 45 [18] e ABNT NBR NM 52 [19], respectivamente. Ainda, para estudar o encaixe natural entre as partículas, calculou-se a porosidade e o fator de empacotamento de cada amostra pela relação entre o volume real dos grãos e o volume aparente dos grãos, parâmetros estes muito utilizados em análises de mecânica dos solos.

Para analisar a forma dos grãos das areias foi realizada uma análise morfoscópica. Para tanto, as amostras foram espalhadas em uma placa de Petri, levadas a uma lupa estereoscópica com ampliação de 32 vezes e, por meio de câmera acoplada e software, foram capturadas as imagens. Com base nas imagens, calculou-se o grau de esfericidade das amostras. Além dessa análise quantitativa, também foi realizada uma análise qualitativa dos grãos, conforme descrito na ABNT NBR 7389 [20].

Também foi realizada a caracterização petrográfica das areias, conforme método prescrito na ABNT NBR 7389 [20]. O experimento foi realizado por meio da análise das lâminas produzidas a partir das areias em estudo em microscópio binocular de luz transmitida com polarizadores cruzados. Quando necessário, além deste exame microscópico, foi realizada difração de raios X, para confirmar a composição mineralógica dos agregados.

As amostras de areia também foram submetidas ao ensaio de cisalhamento direto. $\mathrm{O}$ equipamento de cisalhamento direto, também conhecido como Shear Box Test, da ASTM D 3080 [21], é vastamente utilizado na caracterização geotécnica de solos, sendo empregado especificamente para a determinação de parâmetros como a tensão de cisalhamento, a coesão e o ângulo de atrito interno da amostra. A partir da tensão máxima de cisalhamento $(\tau)$, em função de alguns valores de tensão normal $(\sigma)$, é possível traçar a envoltória de ruptura de Coulomb. O ângulo de atrito é dado pela inclinação dessa reta. A coesão das amostras é dada pelo encontro da envoltória de ruptura com o eixo da tensão cisalhante. No caso específico do material areia, os valores se aproximam de zero e como é sabido que as areias não possuem coesão, ela é considerada igual a zero. $\mathrm{O}$ ensaio foi realizado com a areia seca em estufa para evitar a interferência da umidade, o que poderia sugerir certa coesão (na realidade uma falsa coesão). Foi utilizada uma caixa cisalhadora com área de $5 \mathrm{~cm} \mathrm{x}$ $5 \mathrm{~cm}$, bipartida na horizontal, de forma a proporcionar o cisalhamento da amostra. A parte superior da caixa é fixa e ligada a uma célula de carga de $2 \mathrm{kN}$. A parte inferior fica apoiada sobre rolamentos e na sua lateral é aplicada a força cisalhante com uma velocidade de $0,077 \mathrm{~mm} / \mathrm{s}$. Neste estudo foram utilizadas quatro tensões normais (verticais) pré-definidas: $13,5 \mathrm{KPa} ; 25 \mathrm{KPa} ; 50 \mathrm{kPa}$ e $100 \mathrm{KPa}$.

\subsection{Caracterização das argamassas no estado fresco}

Para determinar a influência das areias no comportamento e nas propriedades da argamassa no estado fresco, foi realizada a caracterização das argamassas produzidas com as cinco amostras de areia. Todas as argamassas foram produzidas com um proporcionamento fixo, em massa, de $1: 0,5:$ 7,0 : 1,9 (cimento, cal, areia seca e água). Este proporcionamento foi definido por ser equivalente a um traço, em volume, de 1:1:6, quando utilizada a areia natural, traço este bastante utilizado para argamassas de assentamento e revestimento.

As argamassas foram produzidas utilizando-se um agitador mecânico com controle de rotação da marca IKA, modelo EUROSTAR 60 Control, provido de haste de hélice com 4 pás. A mistura, em todos as situações, foi realizada com $1105 \mathrm{~g}$ de material seco e com a adição de 249,6 ml de água, em fluxo contínuo, além de rotação constante de 500 rpm por 1 minuto. Após 30 segundos de descanso, para verificar se não havia material anidro na hélice e nos cantos, foi retomada a mistura com rotação constante de 650 rpm por mais 1 minuto, totalizando 2 minutos de mistura. Esse procedimento de mistura foi determinado com base em um estudo piloto, de forma a garantir a homogeneidade das argamassas.

A quantidade fixa de água das misturas foi definida considerando-se o teor ótimo água/materiais secos (H) ajustado para a areia natural, replicando-se o valor obtido para as argamassas produzidas com as demais areias de britagem. Esse parâmetro de dosagem $(\mathrm{H})$ também foi determinado com base em um estudo piloto, em função da trabalhabilidade adequada da argamassa preparada por um profissional pedreiro. O seu valor obtido e adotado em todo o estudo experimental foi igual a $23 \%(\mathrm{H}=23 \%$, em massa). Apesar do teor de água ter sido ajustado tendo-se como referência a areia natural e de ter havido diferenças de consistência entre as várias argamassas (fruto das areias com diferenças em suas características), todas as argamassas do estudo se mostraram trabalháveis, sendo esta uma premissa básica para o critério de fixação da água.

Imediatamente após a mistura, foram conduzidos os ensaios de caracterização das argamassas: determinação da densidade de massa de acordo com a norma ABNT NBR 13278 [22], determinação do índice de 
consistência na mesa de consistência da ABNT (flow table) pela ABNT NBR 13276 [23] e determinação da consistência pela penetração do cone, segundo a ASTM C780 [24].

Também foram calculados os teores das fases constituintes da argamassa no estado fresco, utilizando o método apresentado por Quarcioni et al. [25].

\section{RESULTADOS E DISCUSSÕES}

Neste item são apresentados os resultados de caracterização das areias e das argamassas, além das correlações obtidas entre elas.

\subsection{Caracterização das areias}

A composição granulométrica das cinco amostras de areia pode ser observada na Figura 2. A título de referência, nessa figura está apresentado também o intervalo recomendado pela norma BS 1199 [26] para areias naturais, visando à produção de argamassas de revestimento externo. As areias apresentam, em geral, certa continuidade nas distribuições dimensionais de seus grãos (exceto a areia natural). Pode-se observar, nas curvas granulométricas, que as areias de granito e de micaxisto são as que apresentam os maiores teores de fração fina, abaixo de $0,15 \mathrm{~mm}$ e maiores teores de material pulverulento (Tabela 3). Estas areias se encaixam parcialmente na faixa da BS 1199, caindo fora do intervalo por possuírem uma fração mais fina em sua composição. As areias que mais se encaixam na faixa recomendada pela norma britânica são as oriundas das rochas de dolomito e de quartzito, que também são as distribuições mais grossas, de maior módulo de finura. A areia natural representa a distribuição mais afastada da faixa da norma britânica. Sua curva está praticamente toda fora do intervalo recomendado, deslocada para um campo dimensional menor de partículas (menor módulo de finura dentre todas), apesar das areias de granito e de micaxisto possuírem maiores teores de material pulverulento (passante na peneira $0,075 \mathrm{~mm}$ ).

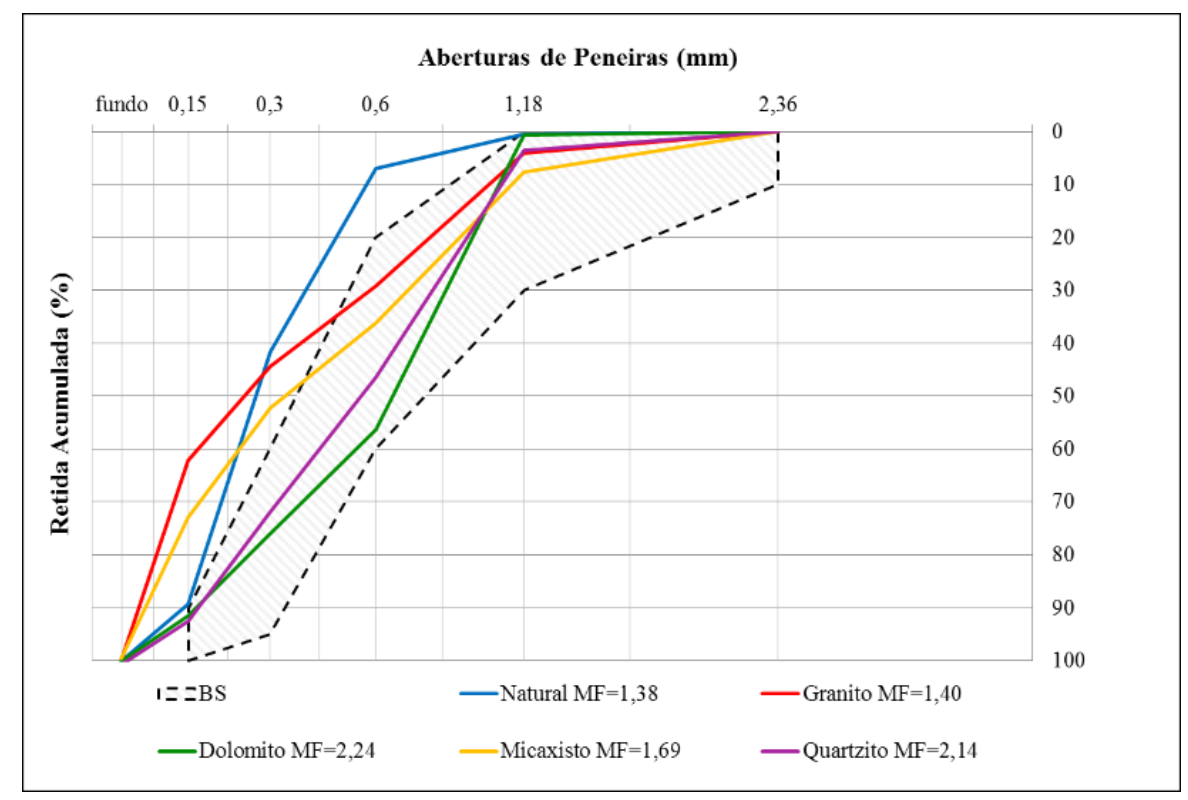

Figura 2: Distribuição granulométrica das areias.

Com base nos valores das massas unitárias e específicas, foi calculado o índice de vazios (e), a porosidade $(\mathrm{n})$ e o fator de empacotamento $\left(\mathrm{E}_{0}\right)$ de cada amostra no estado solto (Tabela 3). Também, com base na curva granulométrica, foram calculados os coeficientes de curvatura $(\mathrm{Cc})$ e de não uniformidade $(\mathrm{Cnu})$.

Todas as areias foram classificadas como finas ou muito finas, tendo em vista o módulo de finura ser inferior a 2,4 (MF $<2,4$ corresponde à areia fina e $\mathrm{MF}<2,0$ à areia muito fina, conforme indicado na versão anterior da ABNT NBR 7211, de 1983). A dimensão máxima característica é igual para todas as areias $(\mathrm{DMC}=1,2 \mathrm{~mm})$, com exceção da areia de micaxisto, que apresentou uma DMC igual a 2,4 $\mathrm{mm}$. As massas unitárias mostraram variação de cerca de $20 \%$ entre as maiores obtidas (areia natural e de dolomito) e a menor (de quartzito). As massas específicas reais dos grãos ficaram próximas para as areias, sendo que a areia natural apresentou o valor mais baixo de todos.

A menor porosidade foi obtida para a areia natural. Os valores de porosidade (e, consequentemente, de 
fator de empacotamento) obtidos são compatíveis com valores encontrados por outros autores que estudaram areias naturais, os quais variaram de $42 \%$ a 55\% [15, 28, 29, 30, 31]. A este respeito, Angelim et al. [32] obtiveram valores de porosidade de $45 \%$ e $47 \%$, respectivamente para uma areia fina e muito fina, ambas naturais. Arnold [13] obteve porosidades de $41 \%$ para a areia natural, enquanto que para a areia britada de rocha basáltica os valores obtidos por essa autora foram de $49 \%$ e $43 \%$, respectivamente para agregados produzidos com britadores VSI e de mandíbulas. Ishikawa e Pereira de Oliveira [15] obtiveram para areias de britagem de granito porosidades entre $41 \%$ e $46 \%$.

Tabela 3: Características das areias estudadas.

\begin{tabular}{|c|c|c|c|c|c|c|c|c|c|c|}
\hline AREIA & TMP & $\mathrm{MF}$ & DMC & MU & $\mathrm{ME}$ & $\mathrm{e}$ & $\mathrm{n}$ & $\mathrm{E}_{0}$ & $\mathrm{Cc}$ & $\mathrm{Cnu}$ \\
\hline Natural & 0,6 & 1,38 & 1,18 & 1,53 & 2,73 & 0,78 & $44 \%$ & $56 \%$ & 0,9 & 2,1 \\
\hline Granito & 25,3 & 1,40 & 1,18 & 1,34 & 2,79 & 1,08 & $52 \%$ & $48 \%$ & 0,6 & 8,4 \\
\hline Dolomito & 0,0 & 2,24 & 1,18 & 1,51 & 2,87 & 0,90 & $47 \%$ & $53 \%$ & 1,2 & 4,6 \\
\hline Micaxisto & 8,0 & 1,69 & 2,34 & 1,29 & 2,93 & 1,27 & $56 \%$ & $44 \%$ & 0,6 & 6,4 \\
\hline Quartzito & 2,0 & 2,14 & 1,18 & 1,26 & 2,81 & 1,23 & $55 \%$ & $45 \%$ & 0,9 & 4,2 \\
\hline \multicolumn{5}{|c|}{$\begin{array}{l}\text { TMP }=\text { Teor de material pulverulento (determinado de acordo com a } \\
\text { NBR NM 46:2003), em \%; }\end{array}$} & \multicolumn{6}{|c|}{$\mathrm{n}=$ Porosidade $=\mathrm{e} /(1+\mathrm{e}) \times 100, \mathrm{em} \%$} \\
\hline \multicolumn{5}{|c|}{$\begin{array}{l}\text { MF = Módulo de finura (calculado de acordo com a NBR NM 248:2003), } \\
\text { adimensional; }\end{array}$} & \multicolumn{6}{|c|}{$\mathrm{Cc}=$ Coeficiente de curvatura $=(\mathrm{d} 30)^{2} /(\mathrm{d} 60 \mathrm{x} \mathrm{d} 10)$, adimensional; } \\
\hline \multicolumn{5}{|c|}{ DMC $=$ Dimensão máxima característica (calculada de acordo com a NBR } & \multicolumn{6}{|c|}{$\begin{array}{l}\mathrm{Cnu}=\text { Coeficiente de não uniformidade }=\mathrm{d} 60 / \mathrm{d} 10 \text { (também denominado, } \\
\text { por outros autores, de } \mathrm{Cu}=\text { coeficiente de uniformidade), adimensional; }\end{array}$} \\
\hline \multicolumn{5}{|c|}{ NM 248:2003), em mm; } & \multicolumn{6}{|c|}{ Critérios de avaliação dos coeficientes: } \\
\hline \multicolumn{5}{|c|}{$\mathrm{MU}=$ Massa unitária, em g/ $/ \mathrm{cm}^{3}$} & \multicolumn{6}{|c|}{$\mathrm{Cc}<1$ ou $\mathrm{Cc}>3$ mal graduado; $1 \leq \mathrm{Cc} \leq 3$ bem graduado; } \\
\hline \multicolumn{5}{|c|}{$\mathrm{ME}=$ Massa específica real dos grãos, $\mathrm{em} \mathrm{g} / \mathrm{cm}^{3}$} & \multicolumn{6}{|c|}{$\mathrm{Cnu}<5$ muito uniforme; $5 \leq \mathrm{Cnu} \leq 15$ de uniformidade média e } \\
\hline
\end{tabular}

Quanto ao coeficiente de curvatura, a areia considerada como de melhor graduação (ou de melhor continuidade de seus grãos) foi a de dolomito (bem graduada: $1 \leq \mathrm{Cc} \leq 3$ ), estando próximas a ela as areias natural e de quartzito. Considerando o critério de uniformidade das areias, que leva em conta a análise do coeficiente de não uniformidade, a areia tida como classicamente muito uniforme foi a natural, já que ela apresentou um Cnu igual a 2,1, portanto muito abaixo do limite de 5. As areias de quartzito e de dolomito vêm na sequência quanto a esse critério, mas já próximas do limite que enquadram as areias como medianamente uniformes. As areias de micaxisto e de granito foram classificadas como de uniformidade média (Cnu entre 5 e 15). De modo geral, confrontando esses dois parâmetros ( $\mathrm{Cc}$ e $\mathrm{Cnu}$ ), pode-se dizer que das cinco areias, quatro delas possuem continuidade nas distribuições dimensionais de seus grãos, com destaque para as areias de dolomito (principalmente) e de quartzito. Já a areia natural mostrou uma distribuição granulométrica uniforme, além de grãos mais finos no geral.

Buscaram-se correlações entre os diversos parâmetros calculados para as areias estudadas (como para o Cc e o Cnu em função da porosidade), mas esses parâmetros não resultaram em boas correlações.

Por meio da morfoscopia das amostras realizadas em lupa estereoscópica (Figura 3), realizou-se a análise qualitativa e a análise quantitativa apresentada na Tabela 4. Estes resultados demonstram como a mineralogia do material influenciou a forma dos grãos.

Tabela 4: Análise morfoscópica qualitativa e quantitativa das amostras de areia.

\begin{tabular}{l|l|l|l}
\hline \multirow{2}{*}{ AREIA } & \multicolumn{2}{|l|}{ ANÁLISE QUALITATIVA } & $\begin{array}{l}\text { ANÁLISE } \\
\text { QUANTITATIVA }\end{array}$ \\
\cline { 2 - 4 } & ESFERICIDADE & FORMA DOS GRÃOS & $\begin{array}{l}\text { GRAU DE } \\
\text { ESFERICIDADE }\end{array}$ \\
\hline Natural & Alta & Subarredondada & 0,70 \\
\hline Granito & Baixa & Angulosa & 0,61 \\
\hline Dolomito & Alta & Subangulosa & 0,66 \\
\hline Micaxisto & Baixa & Subangulosa & 0,52 \\
\hline Quartzito & Baixa & Angulosa & 0,59 \\
\hline
\end{tabular}




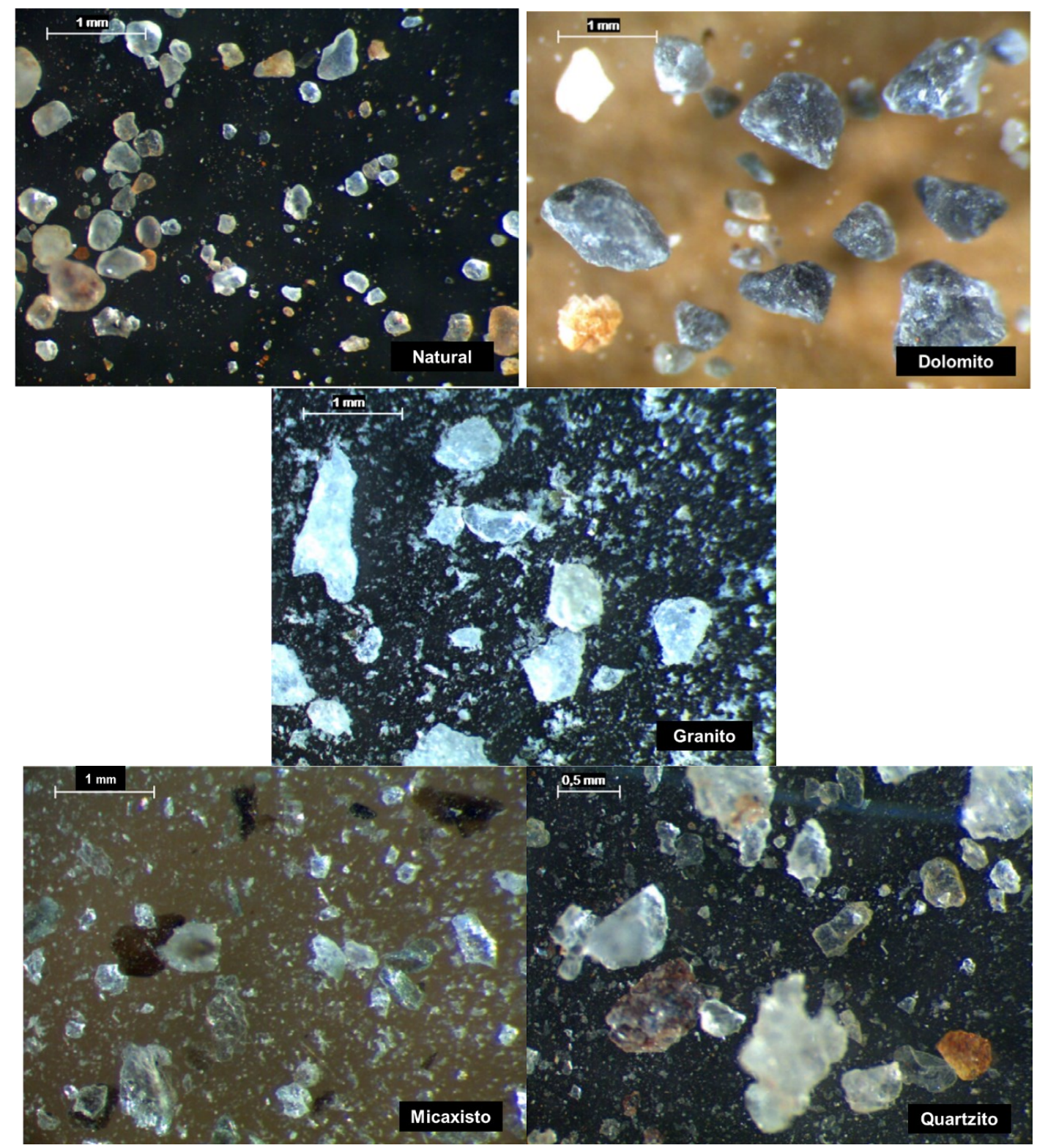

Figura 3: Análise das areias na lupa estereoscópica.

Conforme Tristão [4], a distribuição granulométrica influencia o volume de vazios das areias, no entanto, o efeito da forma dos grãos é um parâmetro ainda mais significativo no resultado do volume de vazios. O efeito da forma dos grãos também pode ser observado no presente trabalho, quando se analisa o índice de vazios, a porosidade e o fator de empacotamento, todos parâmetros inter-relacionados. Conforme comentado anteriormente, a porosidade não pôde ser bem explicada com base nos parâmetros calculados que representam a distribuição granulométrica - Cc e Cnu. A morfologia, por sua vez, é um fator que pode alterar a condição de empacotamento das partículas de uma mistura. Nesse sentido, foram estabelecidas as correlações apresentadas na Figura 4, a seguir. 


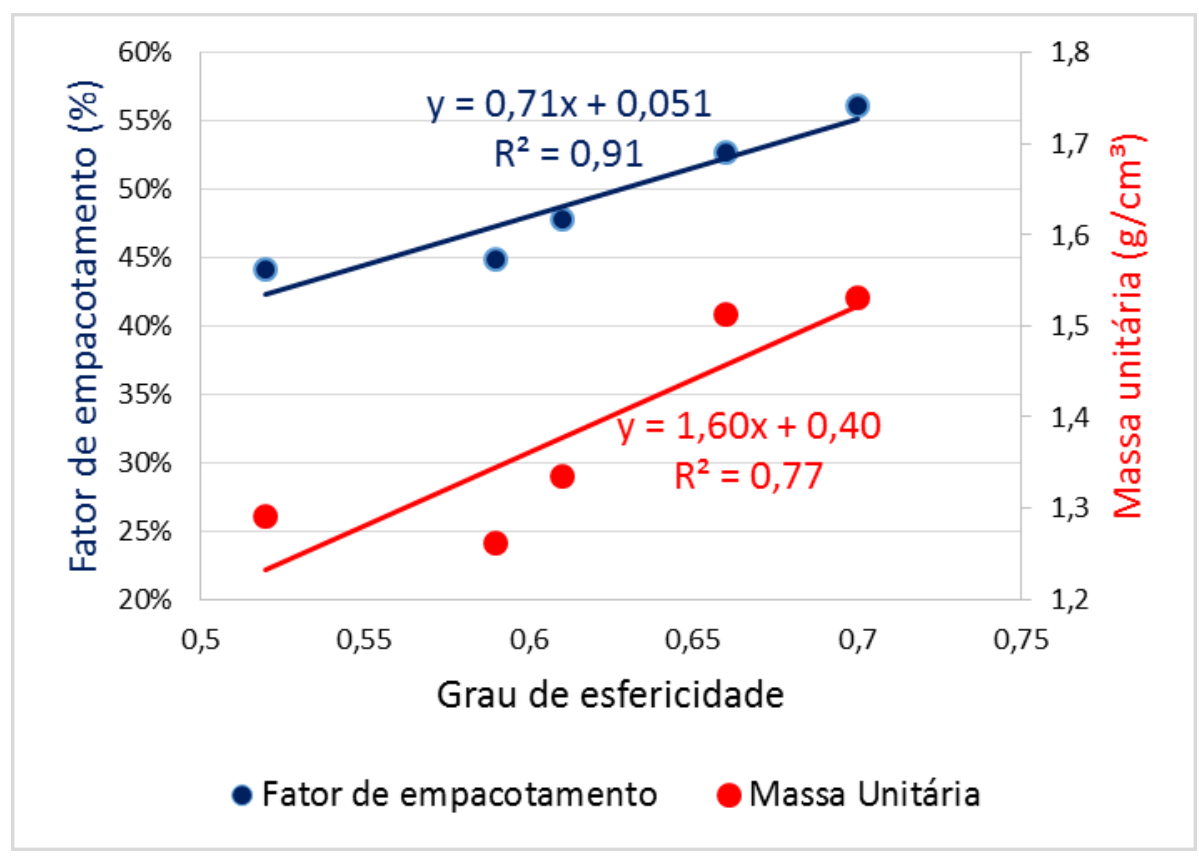

Figura 4: Correlação entre o grau de esfericidade dos grãos e o fator de empacotamento/massa unitária das areias estudadas.

Obteve-se uma forte correlação $\left(\mathrm{R}^{2}=0,91\right)$ entre o fator de empacotamento e o grau de esfericidade das partículas. Também a massa unitária da areia é explicada em grande parte pela esfericidade dos grãos $\left(\mathrm{R}^{2}\right.$ $=0,77$ ). Os resultados confirmam a afirmação de German apud Pileggi [33] que quanto mais irregular a partícula menos eficiente é o empacotamento dos grãos, como ilustrado na Figura 5.

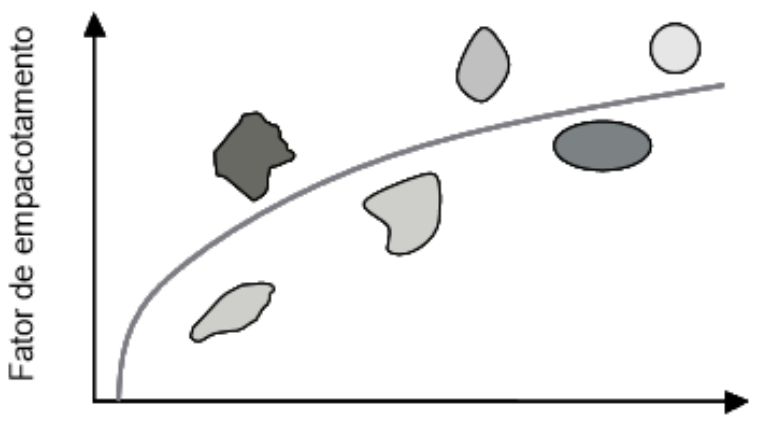

Arredondamento relativo

Figura 5: Ilustração qualitativa da influência da morfologia dos grãos no fator de empacotamento para partículas monodispersas aleatoriamente empacotadas [33].

Quanto mais distante do formato esférico e mais angulosa for a partícula, menor é o grau de empacotamento de uma distribuição, já que as superfícies irregulares de partículas, associadas a uma maior quantidade de arestas nos grãos, levam a uma fricção interparticular [34]. Na prática, o atrito interno entre as partículas é aumentado, o que dificulta a rolagem entre grãos e o alcance de uma melhor acomodação particular, prejudicando, assim, o arranjo ótimo de partículas que leva ao máximo empacotamento.

A Tabela 5 apresenta os resultados obtidos na análise petrográfica. 
Tabela 5: Análise petrográfica das amostras de areia.

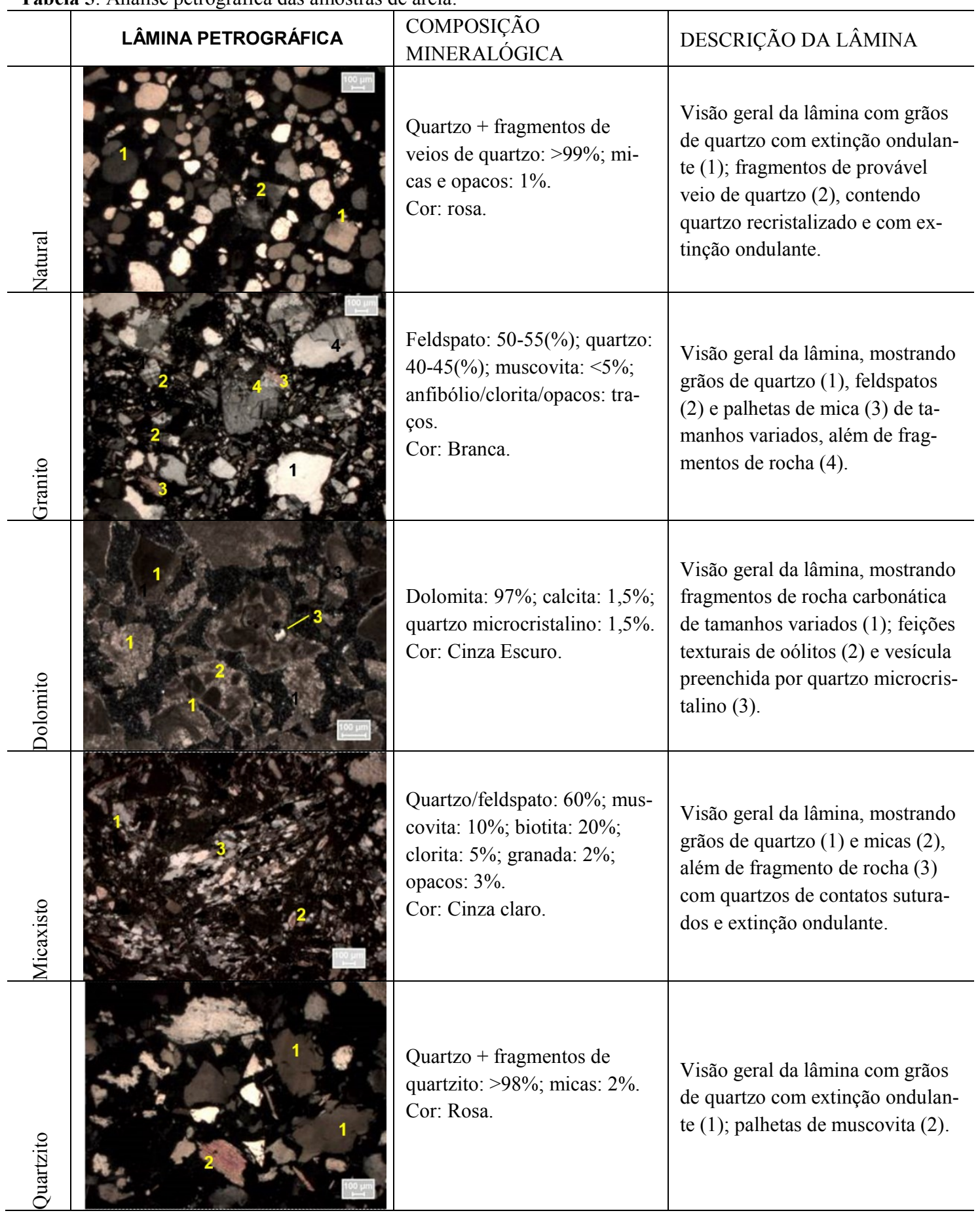

As areias foram submetidas ao ensaio de cisalhamento direto por meio da aplicação de quatro tensões normais. Na Figura 6, de forma a exemplificar, estão apresentadas as curvas de cisalhamento e as curvas expansão/retração vertical da areia de granito para cada uma das tensões normais aplicadas. Este mesmo tipo de gráfico foi elaborado para as demais areias (natural, dolomito, micaxisto e quartzito) e, com base nele, determinadas as tensões máximas de cisalhamento para cada tensão normal, compiladas na Tabela 6. Salienta-se que as demais areias apresentaram gráficos com comportamentos similares ao mostrado na Figura 6. Considerando as cinco areias estudadas em conjunto com as quatro tensões normais - verticais $(13,5 ; 25 ; 50$ e 100 $\mathrm{kPa}$ ) empregadas no ensaio de cisalhamento direto, obteve-se um total de 1220 leituras de tensão cisalhante. 


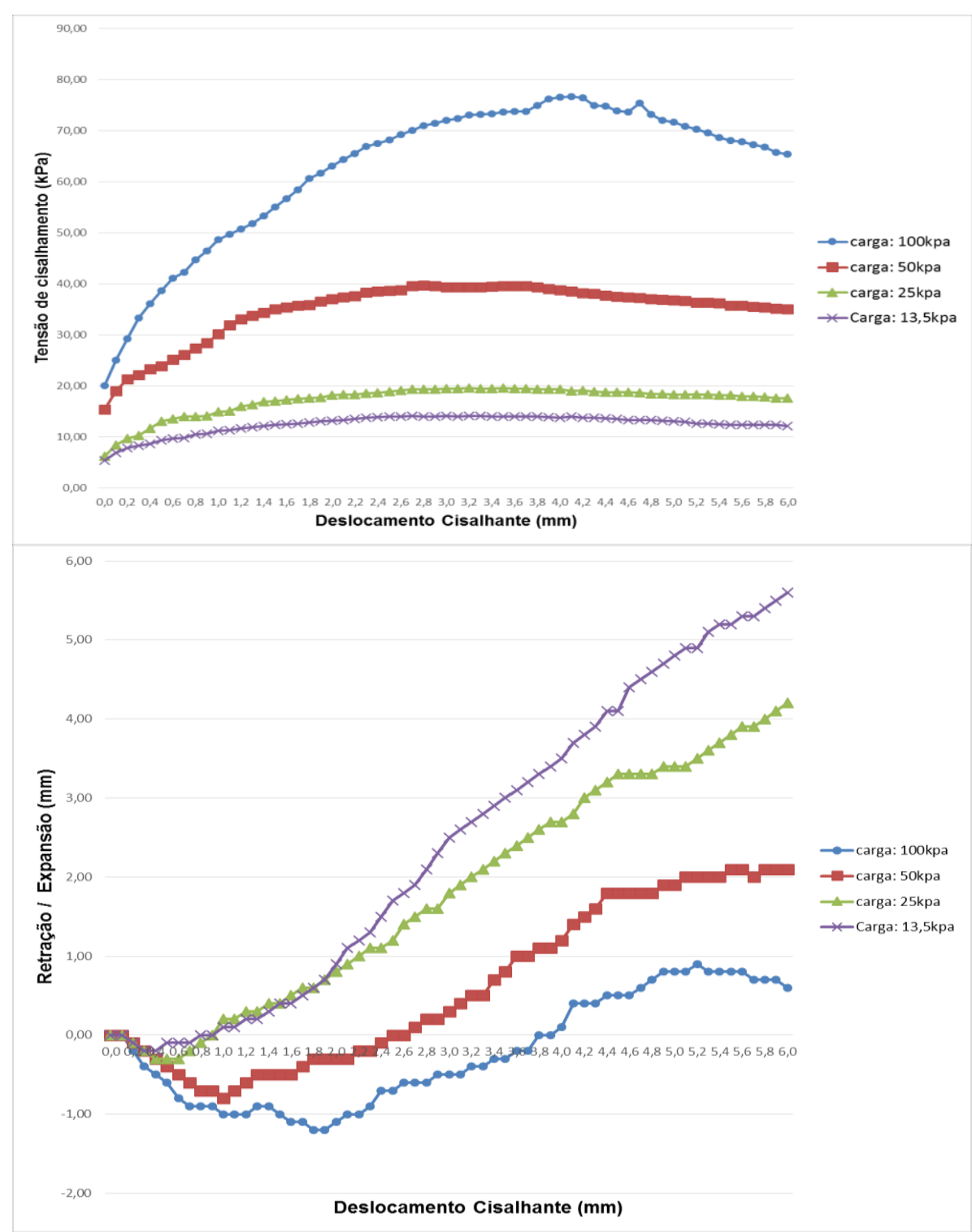

Figura 6: Resultados obtidos no ensaio de cisalhamento direto para a areia de granito.

Tabela 6: Resumo dos resultados obtidos no ensaio de cisalhamento direto das areias.

\begin{tabular}{|c|c|c|c|c|c|c|c|}
\hline \multirow{3}{*}{ AREIAS } & \multirow{2}{*}{\multicolumn{4}{|c|}{$\begin{array}{l}\text { TENSÃO MÁXIMA DE CISALHAMENTO - } \\
\tau(\mathrm{kPa}) \\
\text { TENSÕES NORMAIS APLICADAS }(\sigma)\end{array}$}} & \multirow{3}{*}{$\begin{array}{l}\text { COEFICIENTE } \\
\text { ANGULAR (m) }\end{array}$} & \multirow{3}{*}{$\begin{array}{l}\text { ÂNGULO DE } \\
\text { ATRITO } \\
\text { (GRAUS) }\end{array}$} & \multirow{3}{*}{$\begin{array}{l}\text { COEF. DE } \\
\text { ATRITO } \mu\end{array}$} \\
\hline & & & & & & & \\
\hline & $13,5 \mathrm{kPa}$ & $25 \mathrm{kPa}$ & $50 \mathrm{kPa}$ & $100 \mathrm{kPa}$ & & & \\
\hline Natural & 8,55 & 16,20 & 25,73 & 56,56 & 0,55 & 29 & 0,55 \\
\hline Granito & 14,12 & 19,57 & 39,70 & 76,65 & 0,74 & 36 & 0,74 \\
\hline Dolomito & 11,41 & 21,26 & 23,42 & 71,47 & 0,68 & 34 & 0,68 \\
\hline Micaxisto & 18,63 & 21,26 & 36,01 & 47,70 & 0,35 & 19 & 0,35 \\
\hline Quartzito & 11,53 & 17,38 & 40,60 & 65,55 & 0,64 & 32 & 0,64 \\
\hline
\end{tabular}

Observa-se que, para tensões normais mais baixas, as areias mais esféricas e arredondadas (natural e dolomito) apresentaram as menores tensões de ruptura. Para cada tensão normal determinou-se a máxima tensão cisalhante de cada areia (Tabela 6), resultando, assim, em quatro tensões cisalhantes que proporcionaram a elaboração do gráfico para determinação do ângulo de atrito e inclinação da reta (Figura 7). 


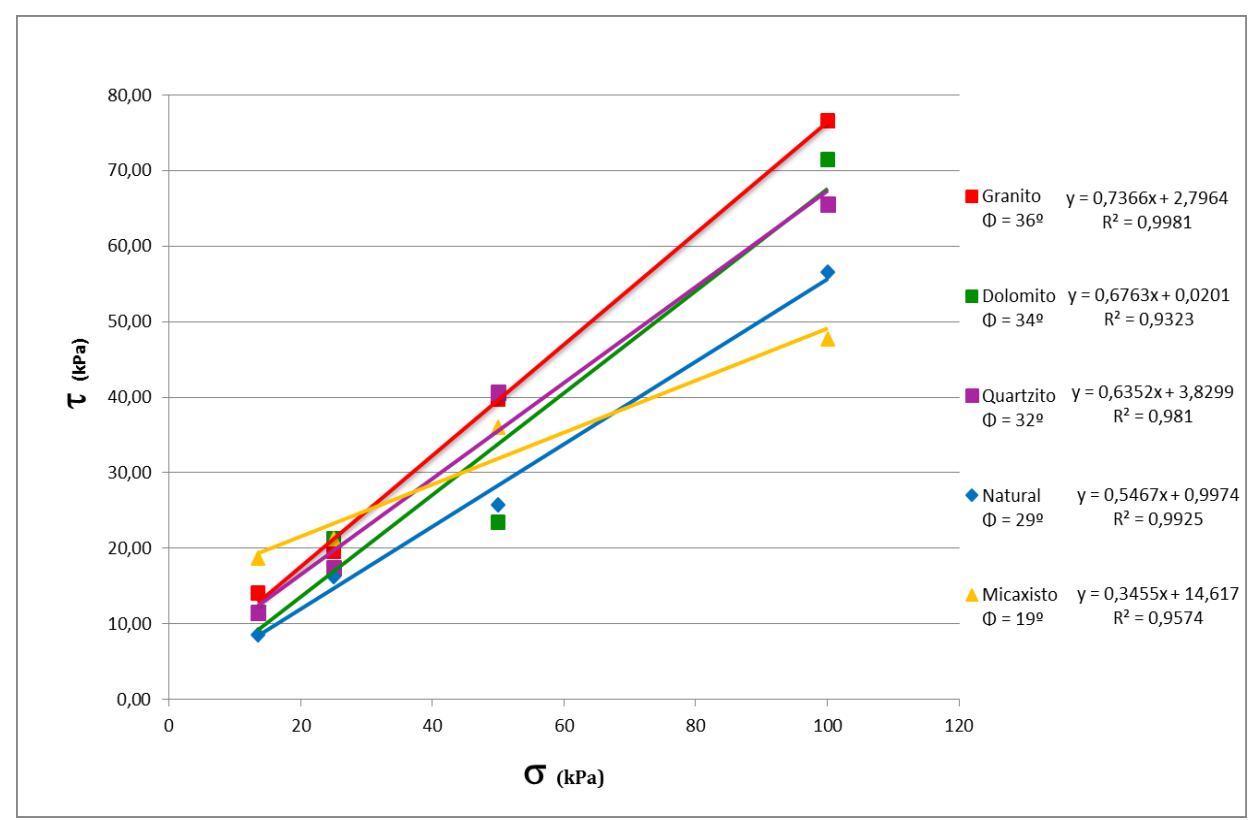

Figura 7: Envoltória de ruptura de Coulomb das amostras de areia.

Os ângulos de atrito das amostras variaram de $19^{\circ}$ a $36^{\circ}$, sendo que a areia de micaxisto foi a amostra que apresentou o menor ângulo de atrito e a de granito apresentou o maior ângulo de atrito. A areia natural apresentou o segundo menor ângulo de atrito.

As amostras analisadas não apresentaram correlação significativa entre o grau de esfericidade (obtido pela morfoscopia) e o ângulo de atrito interno ou coeficiente de atrito (determinado pelo ensaio de cisalhamento direto). Esperava-se que o grau de esfericidade e o ângulo de atrito interno apresentassem uma relação de inversa proporcionalidade entre as variáveis, ou seja, conforme ocorresse a redução da esfericidade da amostra ocorreria um acréscimo no atrito entre as partículas. A influência da esfericidade no ângulo de atrito interno da amostra seria justificada pelo tipo de movimento que as partículas desenvolvem quando estão sendo cisalhadas. Nos materiais granulares (areias), constituídos de grãos isolados e independentes, o atrito é um misto de escorregamento (deslizamento) e de rolamento, sendo afetado fundamentalmente pelo entrosamento ou embricamento dos grãos. Durante o escoamento, as partículas mais esféricas e mais arredondadas (menos angulosas) tendem a rolar umas sobre as outras, em um movimento chamado de rolling friction, que facilita esse escoamento. Já as partículas mais lamelares tendem a deslizar umas sobre as outras no movimento chamado de sliding friction, contribuindo, assim, para o aumento da resistência ao escoamento [35]. No entanto, além da forma do grão, outros aspectos exercem influência no coeficiente de atrito como o empacotamento e a resistência mecânica dos grãos. Nas areias com maior porosidade ocorre uma redução da interação física entre as partículas, devido ao afastamento entre elas. Além disso, as amostras constituídas de rochas menos resistentes, como por exemplo o micaxisto, podem ter os seus grãos cisalhados durante o ensaio, levando a um menor valor de coeficiente de atrito. $\mathrm{O}$ micaxisto apresenta resistência à compressão relativamente baixa quando comparado com outras rochas como o granito. Segundo diversos autores [36, 37, 38], os níveis de resistência à compressão do granito estão entre $170 \mathrm{MPa}$ e $280 \mathrm{MPa}$, enquanto que os do micaxisto ficam em torno dos $85 \mathrm{MPa}$.

A amostra de areia natural apresentou baixo ângulo de atrito por se tratar de um sedimento proveniente da fragmentação da rocha, transportado por ambientes fluviais, o que confere ao material um alto grau de esfericidade e arredondamento, como pode ser visto na Figura 4. Conforme a análise petrográfica, o quartzito proveniente da metamorfização regional ou de contato do arenito tem como principal componente o quartzo e fragmentos de quartzito $(>98 \%)$, contendo pequena quantidade de micas. Essa composição similar à da areia natural estudada ( $>99 \%$ quartzo) confere a esse material uma característica intermediária entre a areia natural e as demais areias de britagem.

Buscou-se também uma correlação entre a porosidade e o coeficiente de atrito das areias, no entanto, nesse caso, não foi obtida correlação significativa. 


\subsection{Influência das areias nas argamassas}

Os resultados médios dos ensaios de caracterização das argamassas no estado fresco estão apresentados na Tabela 7.

Tabela 7: Resultados médios de caracterização das argamassas no estado fresco.

\begin{tabular}{l|l|l|l}
\hline \multirow{2}{*}{ AREIAS } & \multicolumn{2}{|l|}{ CONSISTÊNCIA $(\mathbf{m m})$} & $\begin{array}{l}\text { DENSIDADE DE } \\
\text { MASSA }\left(\mathbf{g} / \mathbf{c m}^{3}\right)\end{array}$ \\
\cline { 2 - 4 } & FLOW TABLE & $\begin{array}{l}\text { PENETRAÇÃO } \\
\text { DO CONE }\end{array}$ & \\
\hline Natural & 348 & $89^{*}$ & 2,04 \\
\hline Granito & 272 & 74 & 1,99 \\
\hline Dolomito & 345 & $89^{*}$ & 2,11 \\
\hline Micaxisto & 256 & 42 & 1,68 \\
\hline Quartzito & 258 & 49 & 1,87 \\
\hline
\end{tabular}

*Atingiu o limite de penetração do cone

No ensaio de penetração do cone, quando foram testadas as argamassas de areia natural e de dolomito, o cone tocou o fundo do recipiente devido à alta fluidez da mistura, ou seja, se o recipiente fosse mais profundo o resultado certamente seria maior. Mesmo assim, a correlação entre os resultados de índice de consistência - flow table e cone foi muito boa $\left(\mathrm{R}^{2}=0,82\right)$. Quando são desprezados os resultados dos ensaios das argamassas de areia natural e dolomito (as quais o cone tocou o fundo do recipiente), a correlação fica ainda melhor, chegando o valor de $\mathrm{R}^{2}$ a 0,99 (Figura 8). Assim, a partir da observação das boas correlações obtidas, optou-se por fazer as discussões referentes à consistência da argamassa e a sua relação com as características das areias com base apenas nos ensaios obtidos pelo método ABNT - Flow table.

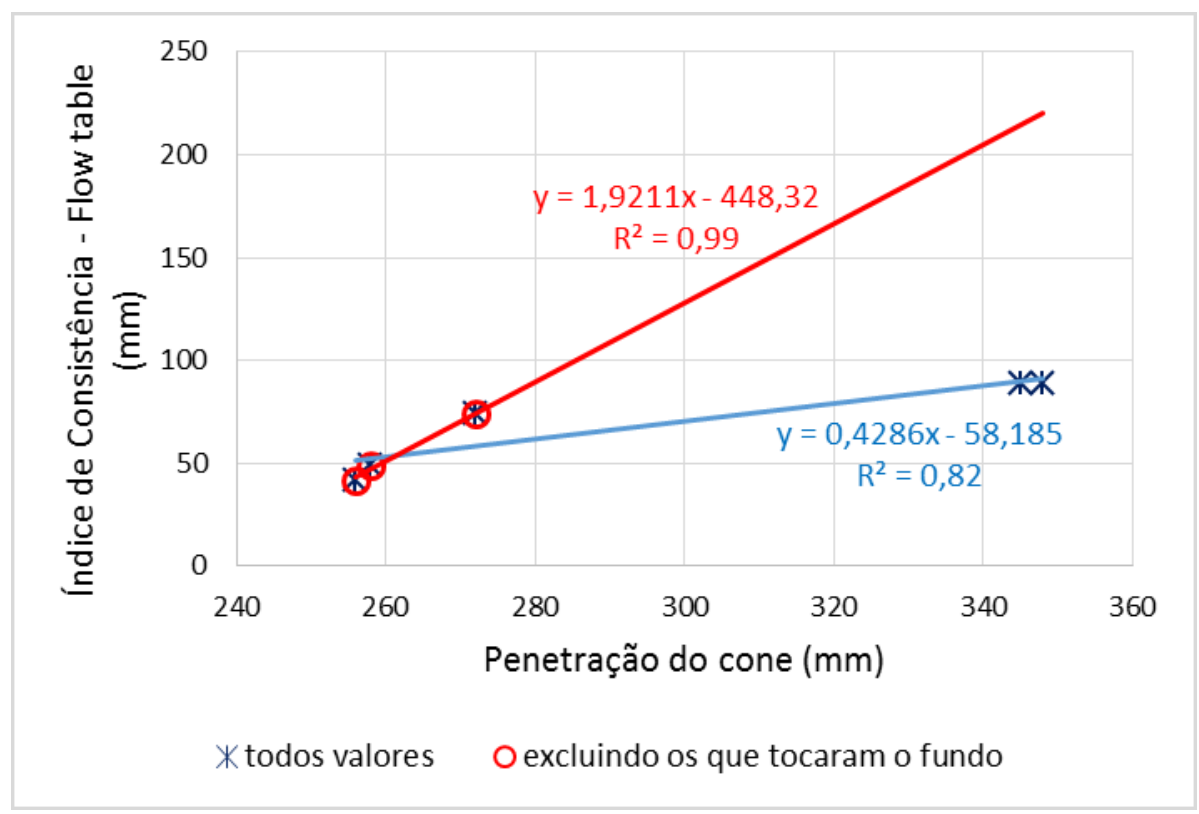

Figura 8: Correlação entre os resultados dos ensaios de índice de consistência (flow table) e penetração do cone (ASTM).

A Figura 9 apresenta os resultados de consistência e densidade de massa mostrados na Tabela 7. Podese observar que os maiores índices de consistência foram medidos para as argamassas elaboradas com a areia natural e de dolomito, e os menores para as areias de quartzito e micaxisto, mostrando diferenças máximas de $26 \%$. Quanto à densidade de massa, os valores variaram entre $1,68 \mathrm{~g} / \mathrm{cm}^{3}$ e $2,11 \mathrm{~g} / \mathrm{cm}^{3}$, respectivamente para o micaxisto e para o dolomito, mostrando uma variação máxima de $20 \%$. 


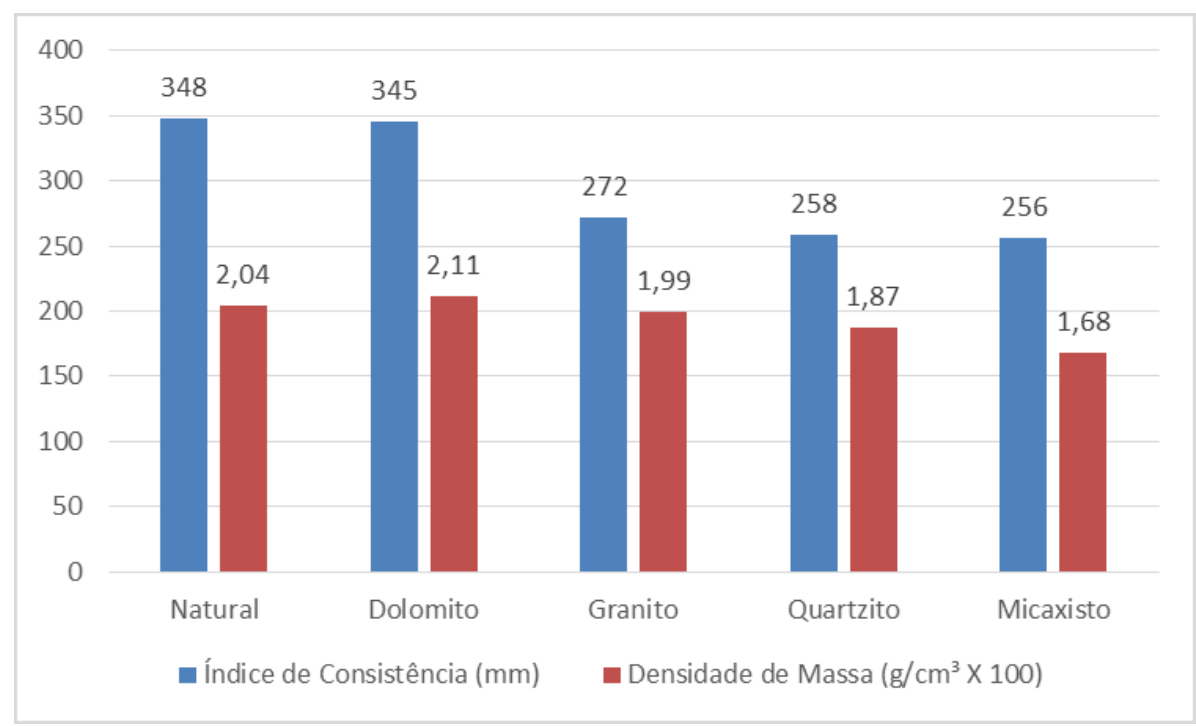

Figura 9: Resultados médios de índice de consistência (flow table) e de densidade de massa das argamassas no estado fresco.

Foi obtida uma correlação razoável entre o índice de consistência e a densidade de massa das argamassas, conforme ilustrado na Figura 10. Uma explicação para esse comportamento é que, com as quedas (sobe e desce) da mesa de consistência, a argamassa mais pesada (densa) espalha-se mais. Salienta-se que retirando o resultado da argamassa elaborada com micaxisto, o valor de $R^{2}$ fica melhor, atingindo 0,76 . A amostra de micaxisto não apresenta um comportamento lógico em relação às demais areias.

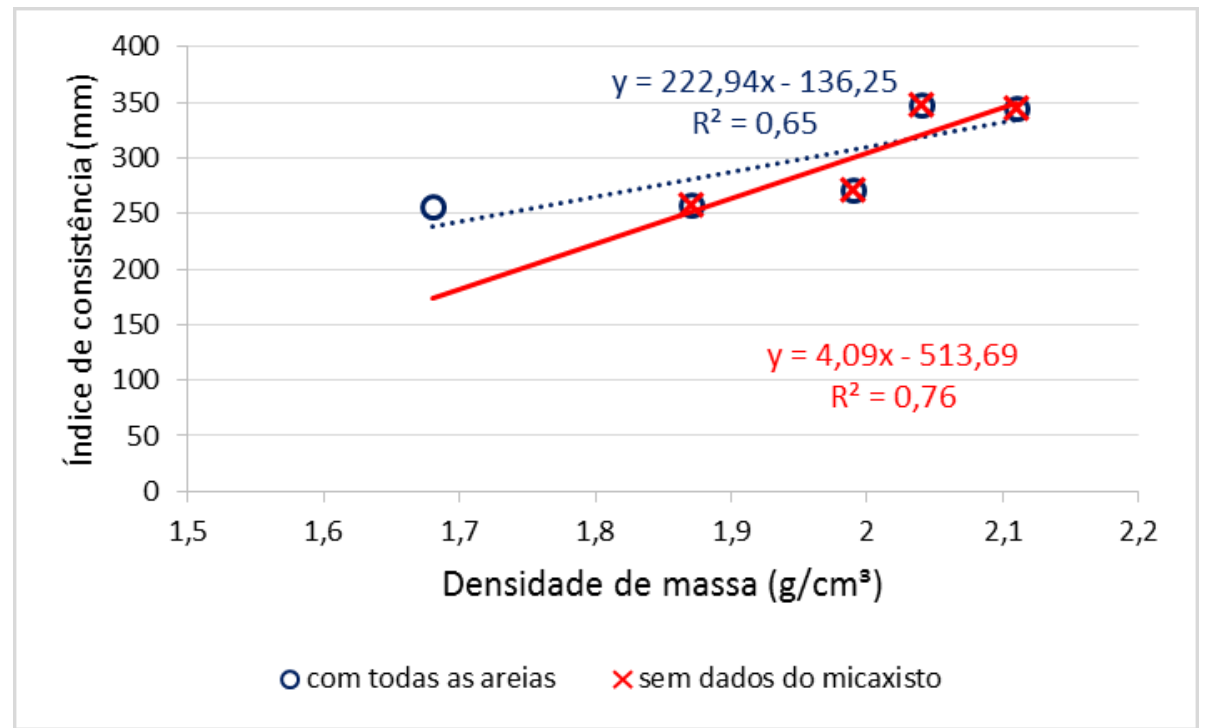

Figura 10: Correlação entre índice de consistência e densidade de massa das argamassas no estado fresco.

Uma análise mais aprofundada irá ressaltar que essa correlação da Figura 10 tem forte respaldo, também, no empacotamento das partículas. Como a quantidade de água e o teor de pasta (em massa) é fixo para todas as misturas, aquelas em que o fator de empacotamento é maior (areias natural e de dolomito) resultaram nos valores mais altos de densidade de massa, o que é um resultado previsível. Contudo, essas argamassas mais empacotadas resultaram, também, nas misturas com maior índice de espalhamento na mesa e maior penetração do cone, ou seja, misturas com maior fluidez. Isto ocorre porque existem menos vazios para a pasta ligante preencher, sobrando assim mais pasta para envolver as partículas ("lubrificando" o sistema) e para afastar mais os grãos, uns em relação aos outros (em comparação às outras misturas). Com o afastamento maior das partículas pela pasta, há uma redução do atrito interno e um aumento da fluidez das misturas.

A Figura 11 apresenta o teor de fases da argamassa no estado fresco, em volume. Nela observa-se que 
apesar do traço em massa ter sido mantido constante, em volume o teor das fases é bem diferente. A argamassa preparada com micaxisto tem um teor de sólidos (areia + cimento + cal) inferior às demais, sendo $23 \%$ menor que o da argamassa elaborada com a areia natural. Também para esta argamassa (com micaxisto), o teor de ar da mistura foi significativamente mais alto. Há uma clara evidência da maior incorporação de ar na argamassa para os agregados mais porosos (menos empacotados). Por sua vez, os sistemas menos empacotados são também aqueles em que as partículas são mais angulosas e menos esféricas (exceto nos casos em que as distribuições granulométricas são essencialmente contínuas, os quais podem, mesmo assim, resultar em arranjos mais empacotados). Por essa razão, há uma constatação de maior incorporação de ar na argamassa conforme os grãos sejam mais angulosos e menos esféricos. Estas questões reforçam a significativa influência do tipo de areia na composição e nas propriedades da argamassa.

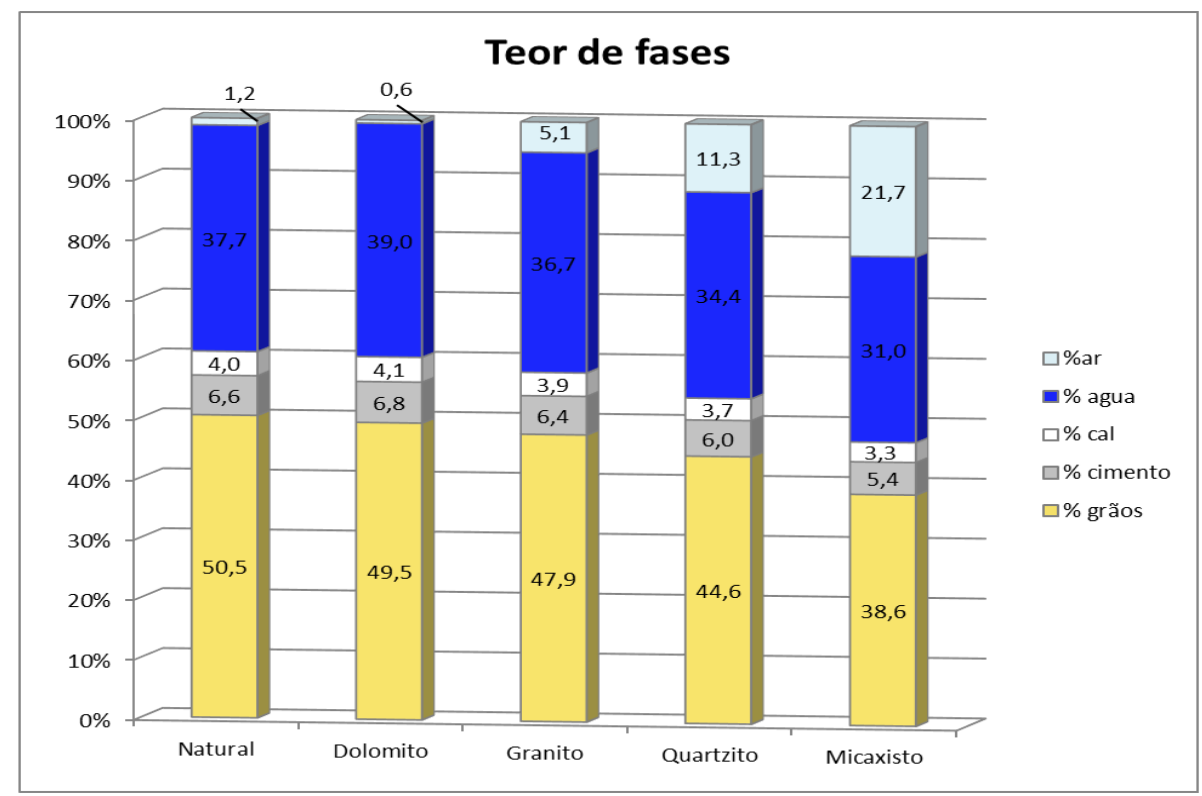

Figura 11: Teor de fases das argamassas no estado fresco, em volume.

A Figura 12 apresenta a correlação obtida entre o teor de sólidos da argamassa e a porosidade calculada para as areias. Observa-se que a porosidade da areia tem forte influência sobre o comportamento das argamassas e que, igualmente a outro comportamento observado, quando se retira o resultado da argamassa com areia de micaxisto a correlação melhora.

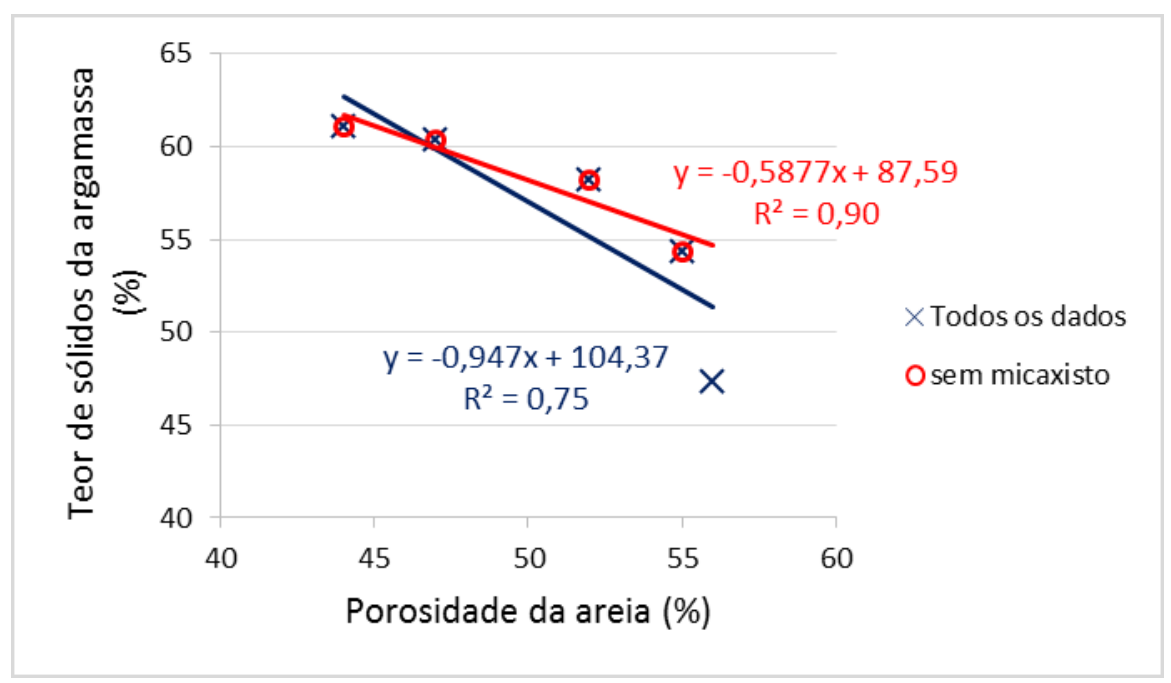

Figura 12: Relação entre o teor de sólidos da argamassa e a porosidade da areia.

A consistência da argamassa apresentou uma ótima correlação linear com a porosidade das areias $\left(\mathrm{R}^{2}=0,94\right)$, como pode ser observado na Figura 13. A porosidade da areia influenciou o teor de fases presen- 
tes nas argamassas que, por sua vez, afetou a consistência da argamassa. Assim, quanto maior a porosidade da areia (ou seja, menor o fator de empacotamento), menor o índice de consistência (argamassa menos fluida), independente de outras características dos agregados, como a forma e a textura. Esta foi uma das constatações mais relevantes do trabalho e, como discutido anteriormente, sistemas mais empacotados (para uma quantidade de pasta fixa) implicam em excedente de pasta para melhor "lubrificar" o conjunto de partículas, afastando os grãos e reduzindo o atrito interno. Salienta-se, ainda, que a pasta não preenche os vazios como um fluido clássico, com efeito, ela envolve os grãos formando uma dupla camada que os afasta proporcionalmente, acomodando o conjunto grão - ar - pasta. Conclui-se, então, que o fator de empacotamento das areias é um dos parâmetros mais relevantes como condicionante da trabalhabilidade das argamassas, analisando-se misturas com uma mesma quantidade de pasta ligante. Por outro lado, considerando que o volume de pasta pode ser ajustado, significa que sistemas de agregados mais empacotados vão demandar menos pasta para a mesma fluidez (trabalhabilidade), o que é um aspecto favorável à economia e à sustentabilidade, resguardadas exigências de propriedades mecânicas de projeto, como aderência e resistência superficial.

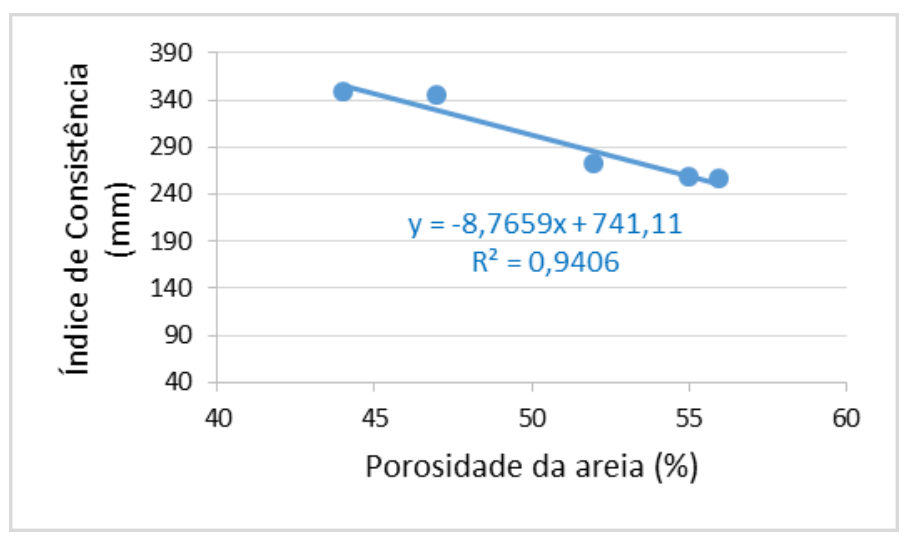

Figura 13: Influência da porosidade da areia no índice de consistência das argamassas.

Para verificar a hipótese proposta neste trabalho, buscou-se também uma correlação entre o ângulo de atrito das areias com a consistência das argamassas, mas este resultou em um $R^{2}$ de 0,06 , indicando não haver correlação. Mendes [35], em uma análise teórica utilizando esferas de vidro ao invés de agregados, também não encontrou relação entre a fluidez das argamassas (avaliada pelo squeeze-flow) e o coeficiente de cisalhamento das partículas.

Alguns trabalhos [6,33,39] apontam para uma influência do coeficiente de atrito dos agregados no comportamento de concretos no estado fresco. Cabe salientar, no entanto, que as argamassas se comportam de forma diferente dos concretos, seja pela quantidade de agregados, seja pela interação dos agregados graúdos (inexistentes na argamassa) com os miúdos. Nas argamassas, o teor de pasta, superior a 50\% em volume, lubrifica e afasta os grãos, de modo que o coeficiente de atrito das areias deixa de ter um efeito majoritário sobre esse novo sistema. Conforme Sobral [39], no caso do concreto, o coeficiente de atrito aumenta com o aumento do diâmetro do agregado, contribuindo assim para a diminuição da trabalhabilidade da mistura. Devido aos efeitos de massa e à baixa superfície específica do conjunto de partículas sólidas no concreto, os agregados graúdos influenciam o comportamento da mistura pela dificuldade de movimentação.

Quanto à densidade de massa das argamassas no estado fresco, esta propriedade, conforme esperado, ficou muito bem explicada $\left(\mathrm{R}^{2}=0,96\right)$ pelo teor de sólidos presentes na argamassa (areia, cimento e cal), como mostrado na Figura 14. Essa propriedade da argamassa é também influenciada pela porosidade da areia, no entanto, com um coeficiente de determinação mais baixo $\left(\mathrm{R}^{2}=0,70\right)$. Nessa linha, Tristão (2005) encontrou uma boa correlação $\left(\mathrm{R}^{2}=0,82\right)$ entre a massa específica das argamassas no estado fresco e o volume de vazios da areia. 


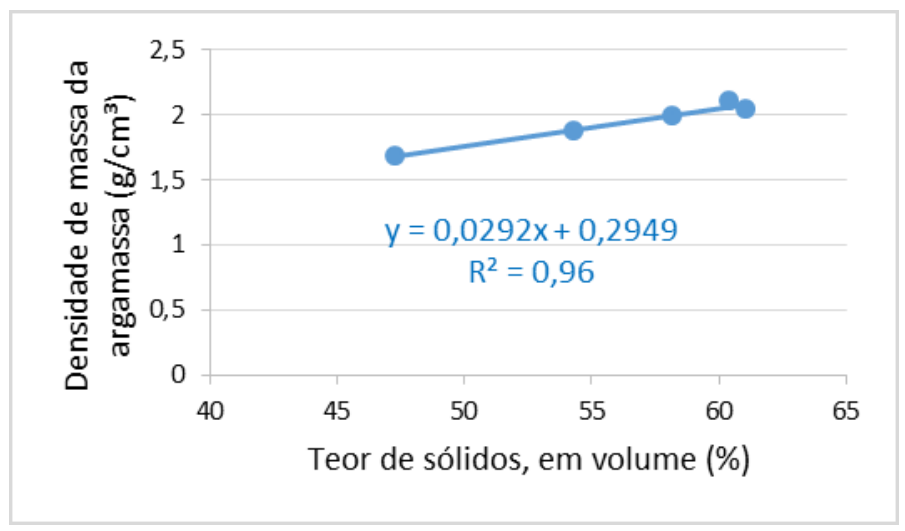

Figura 14: Influência do teor de sólidos da argamassa na densidade de massa das argamassas no estado fresco.

Carneiro, Cincotto e John [40], analisando dados experimentais obtidos por Tristão (1995) com areias naturais, acenaram para o fato de que a massa unitária é um parâmetro relevante no estudo do desempenho das argamassas. Os autores afirmaram que deveria ser aprofundado o estudo das curvas granulométricas das areias a fim de estabelecer melhores correlações com as propriedades das argamassas. Posteriormente, De Shutter e Poppe [41], pesquisando essencialmente areias de forma arredondada (provenientes de rio e mar), concluíram que a massa unitária da areia consiste no parâmetro mais importante para a quantificação da demanda de água das argamassas. Os autores afirmaram que ela é, portanto, um parâmetro muito relevante para a estimativa da influência do tipo de areia nas propriedades de argamassas no estado fresco e endurecido. Nesse sentido, foram analisadasna presente pesquisa as correlações da massa unitária da areia com as propriedades das argamassas no estado fresco, conforme mostrado na Figura 15.

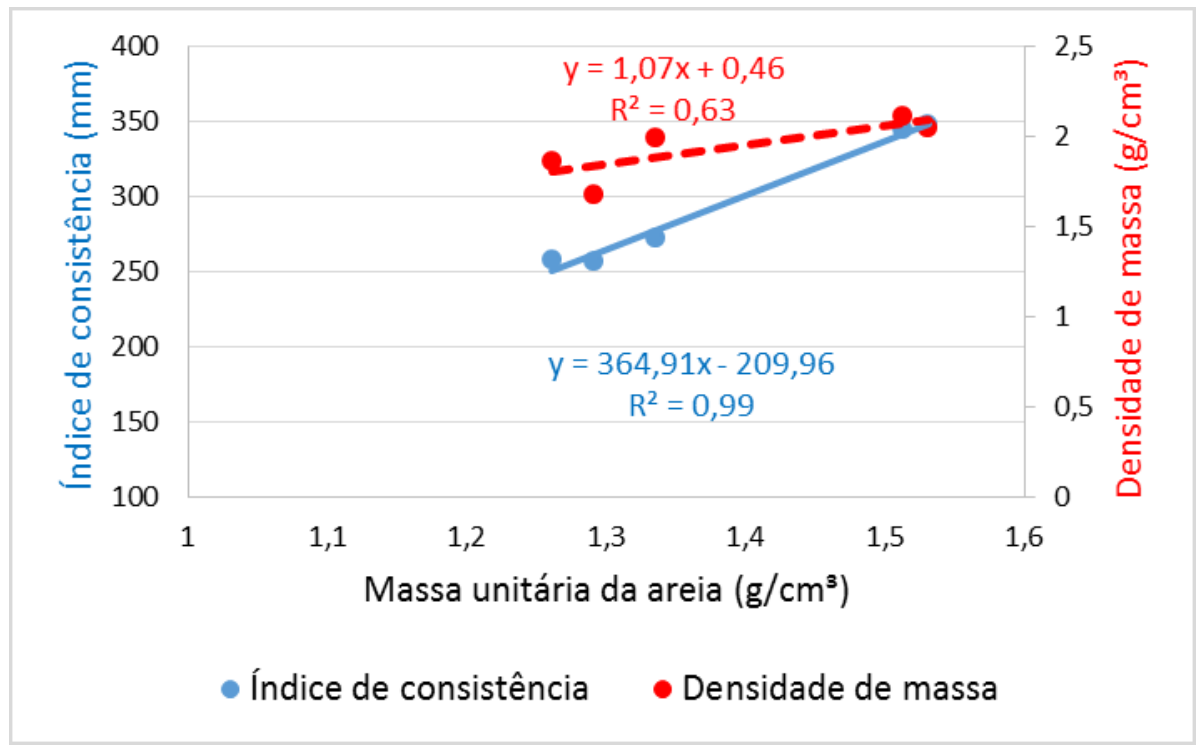

Figura 15: Influência da massa unitária da areia no índice de consistência e na densidade de massa das argamassas.

Observa-se na figura anterior que a massa unitária (MU) da areia explica muito bem o comportamento da consistência das argamassas $\left(\mathrm{R}^{2}=0,99\right)$. Na presente pesquisa, confirmou-se, então, a premissa de que a massa unitária da areia é o parâmetro que melhor explica a consistência (fluidez) da argamassa, com ampliação da conclusão dos autores citados anteriormente para areias de britagem de diferentes litologias, mineralogias e formas. Depreende-se que a massa unitária, ao mesmo tempo, está levando em conta o fator de empacotamento (e a porosidade) do conjunto particular de agregados, bem como tudo aquilo que interfere neste parâmetro, como o tipo de distribuição dos grãos (se contínua ou não), a forma e a geometria das partículas (se mais arredondada ou mais esférica), os teores de finos, as frações finas presentes, etc.

Quanto à densidade de massa das argamassas, o valor do coeficiente de determinação encontrado foi de 0,62 , mostrando que a MU da areia explica somente em parte o comportamento da argamassa. Neste caso, 
a porosidade da areia apresentou uma correlação levemente superior $\left(\mathrm{R}^{2}=0,70\right)$, explicando melhor esta propriedade, uma vez que no seu cálculo leva em consideração também a massa específica das areias, as quais são levemente diferentes (variaram de 2,73 a $2,93 \mathrm{~g} / \mathrm{cm}^{3}$ ).

\section{CONCLUSÕES}

As características das areias exercem forte influência sobre algumas propriedades da argamassa de revestimento no estado fresco, tais como: densidade de massa e consistência.

Observando as cinco areias estudadas, uma natural e quatro de britagem, verificou-se que aquelas de melhor distribuição granulométrica, como o caso da areia de dolomito, ou aquelas com melhor forma dos grãos (mais esféricos e arredondados), como o caso da areia natural, foram as que apresentaram os arranjos de partículas no estado solto mais empacotados, ou seja, com menor porosidade. As misturas mais empacotadas, por sua vez, resultaram em sistemas mais fluidos (menor consistência) e de maior densidade de massa, o que confirma parcialmente a hipótese colocada no início deste trabalho. Em especial quanto à consistência pelo espalhamento na mesa $\mathrm{ABNT}$, esta propriedade da argamassa apresentou uma ótima correlação linear com a porosidade das areias $\left(\mathrm{R}^{2}=0,94\right)$. Esta foi uma das constatações mais relevantes do trabalho, cuja argumentação física se ampara na seguinte afirmativa: sistemas mais empacotados, para uma quantidade de pasta fixa, implicam em excedente de pasta para melhor "lubrificar" o conjunto de partículas, afastando os grãos e reduzindo o atrito interno.

Por outro lado, arranjos mais porosos (menos empacotados) de agregados e, em particular, contendo partículas mais angulosas e menos esféricas, apresentaram menor espalhamento na mesa e menor densidade de massa. No caso da consistência, a areia de micaxisto foi a que produziu a argamassa menos fluída, sendo ela também a que resultou no arranjo mais poroso de partículas na condição seca e solta. No caso da densidade de massa, a justificativa para os menores valores dessa propriedade correspondentes às areias mais porosas se respalda no menor teor de sólidos das respectivas argamassas e no maior teor de ar incorporado, caso majoritário da argamassa produzida com a areia de micaxisto.

O ângulo (ou coeficiente) de atrito das areias não foi um bom parâmetro para explicar o comportamento de consistência ou fluidez das argamassas, como sugerido inicialmente por hipótese. Em se tratando de argamassas, cujo teor de pasta é normalmente superior a $50 \%$, em volume, ocorre "lubrificação" e afastamento dos grãos, de modo que o efeito do coeficiente de atrito das areias sobre a consistência e reologia das argamassas é suprimido ou minimizado, diferentemente do que ocorre com os concretos.

Verificou-se no presente trabalho, por fim, que a massa unitária (MU) da areia explica muito bem o comportamento da consistência das argamassas, com base em uma relação linear $\left(\mathrm{R}^{2}=0,98\right)$, na qual o aumento da MU implica em um aumento proporcional da fluidez (índice de consistência) das misturas. Depreende-se disso que a massa unitária, ao mesmo tempo, está levando em conta o fator de empacotamento do conjunto particular de agregados, bem como tudo aquilo que interfere neste parâmetro, como o tipo de distribuição dos grãos (se contínua ou não), a forma e a geometria das partículas (se mais arredondada ou mais esférica), os teores de finos, as frações finas presentes, etc.

Dada a facilidade na obtenção da massa unitária em agregados miúdos, conjugada ao ótimo resultado desse parâmetro para bem explicar comportamentos das argamassas no estado fresco, tais como, consistência e densidade de massa, conclui-se que a massa unitária pode ser um expressivo parâmetro balizador de aspectos reológicos e de trabalhabilidade das argamassas de revestimento.

\section{AGRADECIMENTOS}

Os autores agradecem à Fundação de Amparo à Pesquisa no Estado de Goiás (FAPEG - Brasil) pela bolsa de formação em nível de mestrado e ao CNPq - Conselho Nacional de Desenvolvimento Científico e Tecnológico, pelas bolsas concedidas aos pesquisadores (PQ). Também agradecem ao DCTT FURNAS - Eletrobras e à empresa Carlos Campos Consultoria e Construções Limitada pela colaboração na caracterização das areias.

\section{BIBLIOGRAFIA}

[1] CARASEK, H. "Argamassas". In: Isaia, G.C. (ed.). Materiais de Construção Civil e Princípios de Ciência e Engenharia de Materiais, São Paulo, IBRACON, pp. 892-944, 2010.

[2] TRISTÃO, F.A. Influência da composição granulométrica da areia nas propriedades das argamassas de revestimento, Dissertação de Mestrado, Programa de Pós-graduação em Engenharia Civil - UFSC, Florianópolis, SC, Brasil, 1995. 
[3] CARNEIRO, A.M.P. Contribuição ao estudo da influência do agregado nas propriedades de argamassas compostas a partir de curvas granulométricas, Tese de Doutorado, Escola Politécnica, Universidade de São Paulo, São Paulo, SP, Brasil, 1999.

[4] TRISTÃO, F.A. Influência dos parâmetros texturais das areias nas propriedades das argamassas mistas de revestimento, Tese de Doutorado, Programa de Pós-graduação em Engenharia Civil - UFSC, Florianópolis, SC, Brasil, 2005.

[5] BASTOS, P.K.X., ALTOMAR NETO, F., BERNARDO, D.S., et al., "Areia de britagem para argamassas e concretos - a experiência de Juiz de Fora, MG”, In: Anais do XI Encontro Nacional de Tecnologia do Ambiente Construido, ENTAC 2006. Florianópolis, 2006.

[6] HU, J. A study of effects of aggregate on concrete rheology. Thesis PHD, Iowa State University, Ames, USA, 2005.

[7] SILVA, N.G., BUEST, G.T., CAMPITELLI, V.C. "Argamassas com areia britada: influência dos finos e da forma das partículas”, In: Anais do IV Simpósio Brasileiro de Tecnologia das Argamassas, IV SBTA ANTAC, pp.11-22, Florianópolis, 2005.

[8] SILVA, N. G. Argamassa de revestimento de cimento, cal e areia britada de rocha calcária. Dissertação de Mestrado, UFPR, Curitiba, PR, Brasil, 2006.

[9] FREITAS, C., COSTA, M.R.M.M. "Estudo da influência da distribuição granulométrica no desempenho de argamassas com areia britada", In: Anais do XIII Encontro Nacional de Tecnologia do Ambiente Construido, ENTAC 2010, Canela, 2010.

[10] WESTERHOLM, M., LAGERBLAD, B., SILFWERBRAND, J., et al., "Influence of fine aggregate characteristics on the rheological properties of mortars", Cement and Concrete Composites, v.30, n.4, pp. 274-282, 2008.

[11] SAMPAIO, R.G.; BASTOS, P.K.X. "Estudo de granulometria de areia de britagem para argamassas de revestimento", In: Anais do VIII Simpósio Brasileiro de Tecnologia de Argamassas, VIII SBTA, Curitiba, 2009.

[12] GUACELLI, P.A.G. Substituição da areia natural por areia de britagem de rochas balsáticas para argamassas de revestimento, Dissertação de Mestrado, Universidade Estadual de Londrina, Londrina, PR, Brasil, 2009.

[13] ARNOLD, D.C.M. Análise da influência da forma dos grãos nas propriedades das argamassas. Dissertação de Mestrado, UNISINOS, São Leopoldo, RS, Brasil, 2011.

[14] ZHOU, W.J., NIU, W., CHEN, J.L., et al., "Influence of the fineness of micro-fines on the performance of cement and mortar", Key Engineering Materials, v.477, pp. 102-107, Apr. 2011.

[15] ISHIKAWA, P.H., PEREIRA de OLIVEIRA, L. "Propriedades da argamassa com areia artificial para revestimento de alvenaria", In: Anais do 4. Congresso Português de Argamassas e ETICS, APFAC, Coimbra, 2012.

[16] CASCUDO, O., CARASEK, H. "O saibro nas argamassas de assentamento: estudo de trabalhabilidade e comportamento no estado endurecido - Parte 1", In: Proceedings of $5^{\text {th }}$ International Seminar on Structural Masonry for Developing Countries, pp. 84-93, Florianópolis, Aug. 1994.

[17] ASSOCIAÇÃO BRASILEIRA DE NORMAS TÉCNICAS. NBR NM 248: Agregados - Determinação da composição granulométrica. Rio de Janeiro, 2003.

[18]__. NBR NM 45: Agregados - Determinação da massa unitária e do volume de vazios. Rio de Janeiro, 2006.

[19] . NBR NM 52: Agregado miúdo - Determinação da massa específica e massa específica aparente. Rio de Janeiro, 2009.

[20] NBR 7389-1: Agregados - Análise petrográfica de agregado para concreto. Parte 1: Agregado miúdo. Rio de Janeiro, 2009.

[21] AMERICAN SOCIETY FOR TESTING AND MATERIALS. ASTM D3080: Standard test method for direct shear test of soils under consolidated drained conditions. Philadelphy, 2011.

[22] ASSOCIAÇÃO BRASILEIRA DE NORMAS TÉCNICAS. NBR 13278: Argamassa para assentamento e revestimento de paredes e tetos - Determinação da densidade de massa e do teor de ar incorporado. Rio de Janeiro, 2005.

[23] _. NBR 13276: Argamassa para assentamento e revestimento de paredes e tetos - Preparo da mistura e determinação do índice de consistência. Rio de Janeiro, 2005. 
[24] AMERICAN SOCIETY FOR TESTING AND MATERIALS. ASTM C 780: Standard test method for preconstruction and construction evaluation of mortars for plain and reinforced unit masonry, Philadelphy, 2012.

[25] QUARCIONI, V.A., CHOTOLLI, F.F., ÂNGULO, S.C., et l., "Estimativas da porosidade de argamassas de cimento e cal pelo método de cálculo de volumes”, Ambiente Construído, Porto Alegre, v.9, n.4, pp. 175-187, out/dez. 2009.

[26] BRITISH STANDARDS INSTITUTION. BS 1199: Specifications for building sands from natural sources, London, 2014.

[27] CAPUTO, H.P. Mecânica dos Solos e suas Aplicações., 6 ed., v.1, Rio de Janeiro, LTC, 2008.

[28] KANNING, R.C. Utilização da cinza de folha de bananeira com adição em argamassas de cimento Portland, Dissertação de Mestrado, Programa de Pós-Graduação em Engenharia e Ciência dos Materiais PIPE, Universidade Federal do Paraná, Curitiba, PR, Brasil, 2013.

[29] SILVA, N.G. Avaliação da retração e da fissuração em revestimento de argamassa na fase plástica. Tese de Doutorado, Programa de Pós-Graduação em Engenharia Civil, Universidade Federal de Santa Catarina, Florianópolis, SC, Brasil, 2011.

[30] ANGELIM, R.R. Influência da adição de finos calcários, silicosos e argilosos no comportamento das argamassas de revestimento, Dissertação de Mestrado, Escola de Engenharia Civil, Universidade Federal de Goiás, Goiânia, GO, Brasil, 2000.

[31] CASALI, J.M. Estudo da interação entre a argamassa de assentamento e o bloco de concreto para alvenaria estrutural: transporte de água e aderência. Tese de Doutorado, Programa de Pós-graduação em Engenharia Civil, Universidade Federal de Santa Catarina, Florianópolis, SC, Brasil, 2008.

[32] ANGELIM, R.R., ANGELIM, S.C.M., CARASEK, H. "Influência da distribuição granulométrica da areia no comportamento de revestimentos de argamassa", In: Anais do V Simpósio Brasileiro de Tecnologia de Argamassas, V SBTA, pp. 159-168, São Paulo, 2003.

[33] PILEGGI, R.G. Ferramentas para o estudo e desenvolvimento de concretos refratários, Tese de Doutorado, Universidade Federal de São Carlos, São Carlos, SP, Brasil, 2001.

[34] CASTRO, A.L., PANDOLFELLI, V.C. "Revisão: Conceitos de dispersão e empacotamento de partículas para a produção de concretos especiais aplicados na construção civil”, Cerâmica, v. 55, n.333, pp.18-32, 2009.

[35] MENDES, T. M. Influência do coeficiente de atrito entre os agregados e da viscosidade da matriz no comportamento reológico de suspensões concentradas heterogêneas, Dissertação de Mestrado, Escola Politécnica da Universidade de São Paulo, São Paulo, SP, Brasil, 2008.

[36] ARAÚJO, W.E.L. Aproveitamento de resíduos da extração de micaxisto em pavimentos flexíveis. Dissertação de Mestrado, EEC, Universidade Federal de Goiás, Goiânia, GO, Brasil, 2008.

[37] COSTA, C.N. Fundamentos de Geotecnia: Introdução à descrição e classificação das rochas. Faculdade de Ciências e Tecnologia, DEC, Universidade Nova de Lisboa, Portugal, 2007.

[38] NETO, J.B. “Critérios de projetos para seleção de materiais”, In: Isaia, G. C. (ed.), Materiais de Construção Civil e Princípios de Ciências e Engenharia de Materiais, São Paulo, IBRACON, pp. 119-138, 2010.

[39] SOBRAL, H.S. Reologia e trabalhabilidade dos concretos. Boletim Técnico, São Paulo, ABCP - Associação Brasileira de Cimento Portland, 1990.

[40] CARNEIRO, A.M.P., CINCOTTO M.A., et al., "A massa unitária como parâmetro de análise das características de argamassa”, Ambiente Construído, v.1, n.2, pp. 37-44, jul/dez. 1997.

[41] SHUTTER, G., POPPE, A.-M. "Quantification of the water demand of sand in mortar", Construction and Building Materials, v.18, pp.517-521, 2004. 